\title{
Effect of Ciprofloxacin versus Levofloxacin on QTc-interval and Dysglycemia in Diabetic and Non-Diabetic Patients.
}

\author{
Nada A. Saad ${ }^{1}$, Ahmed A Elberry², Hazem Samy Matar ${ }^{2}$, and Raghda Hussein ${ }^{1}$ \\ ${ }^{1}$ Beni Suef University Faculty of Pharmacy \\ ${ }^{2}$ Beni Suef University Faculty of Medicine
}

November 15, 2020

\begin{abstract}
Background: Levofloxacin and ciprofloxacin are more commonly used among fluoroquinolone class and the question of cardiac safety and glucose hemostasis of this class has been raised. Objective: To compare intravenous levofloxacin and ciprofloxacin regarding their risk on QTc prolongation and dysglycemia in diabetic and non-diabetic patients. Methods: A randomized prospective study at Beni-Suef university hospital was conducted on 200 adult patients over 6 months. The patients received intravenous levofloxacin $750 \mathrm{mg}$ once daily or ciprofloxacin $400 \mathrm{mg}$ twice daily. Electrocardiogram and fasting blood glucose were obtained from each patient before starting antibiotic, 24 hours, 72 hours after the first dose and 72 hours after antibiotics cessation. Results: The results of the current study showed the relative risk for QTc prolongation with levofloxacin was more than ciprofloxacin by about 4 and 1.5 in diabetic and non-diabetic patients, respectively. The relative risk for dysglycemia with levofloxacin was 2.28 and 1.39 times more than ciprofloxacin in diabetic and non-diabetic patients, respectively. Conclusion: The present study showed that the risk for QTc prolongation and hyperglycemia was greater with levofloxacin than ciprofloxacin in diabetic and non-diabetic patients. In addition, the risk for hypoglycemia was greater with levofloxacin than ciprofloxacin in non-diabetic patients.
\end{abstract}

\section{Hosted file}

Nada A.Saad final IJCP manuscript.pdf available at https://authorea.com/users/375824/ articles/493021-effect-of-ciprofloxacin-versus-levofloxacin-on-qtc-interval-anddysglycemia-in-diabetic-and-non-diabetic-patients

\section{Hosted file}

Figures Nada IJCP.pdf available at https://authorea.com/users/375824/articles/493021-effectof-ciprofloxacin-versus-levofloxacin-on-qtc-interval-and-dysglycemia-in-diabetic-andnon-diabetic-patients

\section{Hosted file}

Tables NADA IJCP.pdf available at https://authorea.com/users/375824/articles/493021-effectof-ciprofloxacin-versus-levofloxacin-on-qtc-interval-and-dysglycemia-in-diabetic-andnon-diabetic-patients 